\title{
Location Routing Inventory Problem with Transhipment Points Using $p$-center
}

\author{
S. S. R. Shariff*, N. S. Kamal, M. Omar and N. H. Moin \\ Centre for Statistical and Decision Science Studies, Faculty of Computer \\ and Mathematical Sciences, Universiti Teknologi MARA, 40450 Shah Alam, \\ Selangor, Malaysia \\ *Corresponding Author: shari990@ @alam.uitm.edu.my
}

Received 4 September 2016; Accepted 18 October 2016; Publication 29 October 2016

\begin{abstract}
Location Routing Inventory Problem with Transhipment (LRIP-T) is a collaboration of the three components in the supply chain which are locationallocation; vehicle routing and inventory management problems that allow transhipment process, in a way that the total system cost and the total operational time are minimized. This study is to determine a set of customer points to act as the transhipment point as and when it is necessary, based on the surplus quantities it has, the quantities to ship to the needing customers and the sequence in which customers are replenished by homogeneous fleet of vehicles. The transhipment point is selected from the existing customers using $p$-center. The performance of the selection is evaluated using a set of benchmark data and a real life data. For the real life data, sensitivity analysis based on the number of distribution centres and size of lorries are presented. Results show important savings achieved when compared to the existing model in solving the supply chain problem.
\end{abstract}

Keywords: Location Inventory Routing Problem with Transhipment, p-center.

Journal of Industrial Engineering and Management Science, Vol. 1, 59-72.

doi: 10.13052/jiems2446-1822.2016.004

(C) 2016 River Publishers. All rights reserved. 


\section{Introduction}

Location routing inventory problem (LRIP) is an integration of three keys logistics decision problems which are location-allocation, vehicle routing and inventory management. LRIP arises when decisions on the three problems must be taken simultaneously. According to [1,3], LRIP in the distribution systems is to allocate depots from several potential locations to schedule the routes for vehicle in meeting the customer's demand and to determine the inventory policy based on the information of customer's demands in order to minimize the system's total costs. Location inventory routing problem (LRIP) is a branch of logistic study that is not widely explored by the researchers due to the interrelated decision areas. However, excellent integration consequently presents significant saving costs as simultaneous decisions imposed in solving the problems.

Not having enough stock to fulfill the customer's demand or stock out is one of issues in the supply chain distribution. This unexpected situation occurred when there is an excess demand that lead to falling of inventories. When this happened, customers tend to purchase goods at another store or does not purchase at all. In addition, when a substitution is made, the retailer and supplier lose their potential sale as customers start to switch to another substitute and they may experience customer's dissatisfaction, worst outcome is losing a customer. It is vice versa of surplus where surplus is described as a situation to retain excess inventory. Surplus can cause profit loss to a company. When there is a surplus, it takes up space and increased holding costs. We have seen the impact of both issues in supply chain, thus we consider incorporating the transshipment process in order to prevent it from happening.

Transshipment has important role in the supply chain as it allows the goods to be shipped from depot to a customer or from a customer with excess stock to be shipped to another customer. It is profitable to the supplier as they can save the transportation cost in terms of delivering goods to the respective customer and at the same time, customer can also save cost in terms of storage space and obsolete the access stock. Several studies implemented transshipment and proved that it is effective compared with the LRIP without transshipment. Researchers tend to integrate transshipment with inventory routing problem (IRP) such as researchers [2, 4-6]. IRP is the combination of two problems in operation research; vehicle routing and inventory and IRPT is the extension of IRP with insertion of transshipment. In both studies they used the customers as the transshipment points and we also implemented the similar technique. The transshipment is only allowed when the location 
of transshipment point with retailer are nearer compared to the location of supplier. It is profitable to the supplier as they can save the transportation cost because of the short distance of travel to the customers. In this study, we consider LRIP-T or Location Routing Inventory Problem with Transshipment by applying $p$-center to select the transshipment center and apply the model to solve a real world problem.

\section{Research Methods}

\section{Model}

The model used is adapted from the earlier study [9] in which the transshipment cost is incorporated into total system cost of existing model adapted from [8]. $p$-center model is used to select the best transshipment point. In $p$-center problem the maximum distance between the distribution point and customer's node is minimized.

where

$r_{i j}$ : the cost (unit) of transshipping product from $i$ to $j$

$Q_{v i j}$ : the quantity transshipped from customer $i$ in period $t$

MaxD: the total cost at the maximum distance,

Maximize $\sum_{t=1}^{l} \sum_{k=1}^{K} \sum_{h=1}^{N+M} \sum_{g=1}^{N+M} D_{h g} \cdot W_{h g k t}$

The formulation of the objective function is as below:

Minimize

$$
\begin{aligned}
\operatorname{MaxD}+\sum_{j=N+1}^{N+M}\left(E_{j}+\right. & \left(\sum_{t=1}^{l}\left(B_{j}+Y_{j}\right) H_{j}(t)+q_{j} \cdot \frac{P}{l} .\right. \\
& \left.\sum_{i=1}^{l}\left(V_{j}(t)+\alpha_{j} \gamma_{j}(t)\right)+B_{j}\right) \cdot A_{j}
\end{aligned}
$$

Subject to:

$$
\begin{gathered}
\sum_{k=1}^{K} \sum_{h=1}^{N+M} W_{g i k t}=1, \text { for all } i, t \\
\sum_{g=1}^{N+M} W_{g h k i}-\sum_{g=1}^{N+M} W_{h g k i}=0, \text { for all } h, k, \text { and } I
\end{gathered}
$$




$$
\begin{gathered}
\sum_{h=1}^{N+M} \sum_{g=1}^{N+M} W_{g h k i} \leq 1, \text { for all } k, \text { and } t \\
\beta_{k}^{t}(i) \leq C K \text {, where } i \in\{0,1,2, \ldots, N\} \\
\tau_{i}(t) \leq U\left(f_{i}(t)\right), \text { for all } I \\
\sum_{h=1}^{N+M} W_{i h k t}-\sum_{h=1}^{N+M} W_{j h k t}-S_{i j} \leq 1, \text { for all } i, j, k \text { and } t \\
W_{g h k t} \in\{0,1\}, \text { for all } g, h, k \text { and } t \\
A_{j} \in\{0,1\}, \text { for all } j \\
S_{i j} \in\{0,1\}, \text { for all } i \text { and } j \\
O_{j k t} \in\{0,1\}, \text { for all } j, k, \text { and } t \\
O_{j} \in\{0,1\}, \text { for all } j
\end{gathered}
$$

The objective function is to minimize the total system cost expressed by the summation of logistics center's set up cost, transportation cost and inventory cost. Constraint (1) ensures that each customer appears in only one route during period $t$. Constraint (2) states that every point entered should be the same point the vehicle leaves. Constraint (3) insures that each route only served by one logistics center. Constraint (4) and (5) are the statement for any period, in any point the total load is less than the vehicle capacity and the actual volume is equal or less than expected volume. Constraint (6) states that a customer can be allocated to a logistics center if there is a route passed by the customer. Constraint (7-11) insures the decision variable's integrality.

The following notations are used to describe the formulation.

$N$ : number of customer points

$M:$ number of logistics centers

$h$ : index of customer point or logistic centers $(1 \leq h \leq N+M)$

$g$ : index of customer point or logistic centers $(1 \leq g \leq N+M)$

$i$ : index of customer point $(1 \leq i \leq N)$ 
$j$ : index of logistics center $(N+1 \leq j \leq N+M)$

$k$ : index of vehicles or routes $(1 \leq k \leq K)$

$t$ : index of time periods of planning horizon $(p)(1 \leq t \leq p)$

$E_{j}$ : cost to establish the logistics center $j$

$D_{h g}$ : distance between point $h$ and point $g$

$P$ : length of the planning horizon

$C K$ : capacity of vehicles

$c$ : unit cost of vehicles

$B_{j}$ : cost of dispatching the product from factory to logistics center $j$

$\alpha_{j}$ : probability of being reused after a circulation

$q_{j}$ : holding cost of products (in unit) at logistics center $j$

$Y_{j}$ : ordering cost of every time in logistics center $j$

$L_{j}$ : lead time in logistics center $j$ where, $L_{j} \leq P / p$

$V_{j}(t)$ : logistics center's $\mathrm{j}$ inventory level start at period $\mathrm{t}$, where $V_{j}(t=0)=0$ stands for inventory is zero at the initial stage of planning horizon

And the decision variables are:

$W_{h g k t}: 1$, if point $h$ immediately go to point $g$ on route $\mathrm{k}$ in period $t ; 0$, otherwise

$S_{i j}: 1$, if customer $i$ is allocated to logistics center $j ; 0$, otherwise

$A_{j}: 1$, if logistics center $j$ is opened; 0 , otherwise

$O_{j k t}: 1$, if route $k$ is served by logistics center $j$ in period $t ; 0$, otherwise

$H_{j}(t): 1$, if there exists an order for new product at logistics center $j ; 0$, otherwise

$R_{i}(t)$ : actual collection volume from customer $i$ in period $t$

\section{Data Analysis \& Results}

The analysis is divided into two sections: (1) on benchmark data for method validation and (2) on real life data for application.

\subsection{Data Preparation (Benchmark Data)}

Data are adapted based on [8,9] and used based on the following assumptions. First, there are 5 candidates of logistics centers and 15 customers, the capacity of vehicles $(C K)$ is 125 units, the unit cost of vehicles $(c)$ is 1/unit distance and the probability of being reused after a circulation $\left(\alpha_{j}\right)$ is 0.9 . In addition, we assume the expected distribution demand is randomly populated and obey the Poisson distribution with $\lambda_{i}=2$ and $\delta_{i}=1$. Tables 1 and 2 present the parameter values of logistics centers and customer points. 
64 S. S. R. Shariff et al.

Table 1 Logistics centers

\begin{tabular}{cccc}
\hline Logistics Centers & Coordinates & $\alpha_{j}$ & Setup Cost \\
\hline D1 & $(43,49)$ & 25 & 10,000 \\
D2 & $(1,12)$ & 20 & 12,000 \\
D3 & $(41,30)$ & 30 & 14,000 \\
D4 & $(5,58)$ & 10 & 13,000 \\
D5 & $(24,19)$ & 15 & 12,000 \\
\hline
\end{tabular}

Table 2 Customer points

\begin{tabular}{ccc}
\hline Customer Points & Coordinates & Demand \\
\hline C1 & $(15,3)$ & 42 \\
C2 & $(18,24)$ & 56 \\
C3 & $(2,59)$ & 53 \\
C4 & $(9,6)$ & 34 \\
C5 & $(49,54)$ & 48 \\
C6 & $(33,10)$ & 61 \\
C7 & $(30,50)$ & 37 \\
C8 & $(24,59)$ & 45 \\
C9 & $(3,35)$ & 48 \\
C10 & $(33,21)$ & 68 \\
C11 & $(45,27)$ & 32 \\
C12 & $(46,6)$ & 69 \\
C13 & $(24,32)$ & 45 \\
C14 & $(28,33)$ & 62 \\
C15 & $(2,0)$ & 47 \\
\hline Total & & 747 \\
\hline
\end{tabular}

\subsection{Results on Benchmark Data}

In earlier study, the transshipment point is determined based on $p$-center. In the actual scenario, the total system cost is the summation of establishing cost of logistics centers, transportation cost and inventory cost. There are some modified costs for LRIP-T in this study.

i. Logistics Center Establishment Cost - No establishment cost needed as the transshipment center will be selected among the customers.

ii. Transportation cost - Transportation cost covers the from the distribution centers and from the transshipment centers.

iii. Inventory cost - The inventory level at the transshipment center is assumed to be zero, or the center is assumed not to keep any stock.

Table 3 shows that the logistics center D1 is determined to be the best center with the lowest average travelled distance of $96.67 \mathrm{~km}$ when the supply is 
Table 3 Results for limited supply

\begin{tabular}{ccccc}
\hline $\begin{array}{c}\text { Logistics } \\
\text { Center }\end{array}$ & $\begin{array}{c}\text { Total Distance } \\
(\mathrm{km})\end{array}$ & $\begin{array}{c}\text { Average Distance } \\
(\mathrm{km})\end{array}$ & $\begin{array}{c}\text { Average } \\
\text { Distance/Vehicle } \\
(\mathrm{km})\end{array}$ & $\begin{array}{c}\text { Average Waste } \\
(\text { unit })\end{array}$ \\
\hline D1 & 690.69 & 46.05 & 230.23 & 51 \\
D2 & 725.91 & 48.39 & 241.97 & 51 \\
D3 & 1022.31 & 68.15 & 340.77 & 51 \\
D4 & 956.7 & 63.78 & 318.9 & 51 \\
D5 & 749.79 & 49.99 & 249.93 & 51 \\
\hline
\end{tabular}

unlimited and $46.05 \mathrm{~km}$ only when the supply is limited [9]. Considering the average traveled distance at $46.05 \mathrm{~km}$, this means that the total cost is equal to $46.05 \times 747=34399.35$.

In the second phase, a transshipment point is determined based on the notion of $p$-center. The transshipment process is considered only for the case when supply is limited.

Initial sets of routes are chosen and MaxD is calculated and minimized. Each customer from $\mathrm{C} 1$ up till $\mathrm{C} 15$ has equal chance of being chosen as the transshipment point. Total transportation system cost is calculated and the best result is based on the set that produces the lowest cost.

Table 4 shows the final answer that lists the customers that being covered by $\mathrm{D} 1$ as the logistics center and those that being covered by $\mathrm{C} 11$ as the transshipment point. This also shows the total delivery cost (in $\mathrm{km}$ ) of 19, 756.8 compared to 34399.35 . This means that LRIP-T model has performed tremendously well in order to save the total costs for all the three systems; location, inventory and routing.

Table 4 Coverage of logistics center and the transshipment point

\begin{tabular}{cccc}
\hline \multicolumn{2}{c}{ D1 Coverage } & \multicolumn{2}{c}{ C11 Coverage } \\
\hline Customer Points & Cost & Customer Points & Cost \\
\hline C2 & 2287.6 & C1 & 775.6 \\
C3 & 2276.4 & C5 & 336.0 \\
C4 & 1867.6 & C9 & 700.0 \\
C6 & 1554.0 & C14 & 400.4 \\
C7 & 2632.0 & C15 & 532.0 \\
C8 & 1920.8 & & \\
C10 & 1103.2 & \\
C12 & 2105.6 & \\
C13 & 1265.6 & \\
\hline \multicolumn{4}{c}{ Total cost $=19756.8$} \\
\hline
\end{tabular}




\subsection{Real-Life Data}

In order to apply the model, a case study on delivery of frozen chicken by a local company in Selangor, Malaysia is chosen. The main distribution centre is located in Semenyih, Selangor, however, the model is applied to solve its delivery problem to its 36 customers in another state, Pahang, Malaysia. Figure 1 shows a map of chicken order for a month in Pahang, Malaysia and the customers are clustered in seven (7) areas, as some (for example C6-C28) customers are quite close to each other. There are a lot of independent agents who operate from grocery shops or homes in each

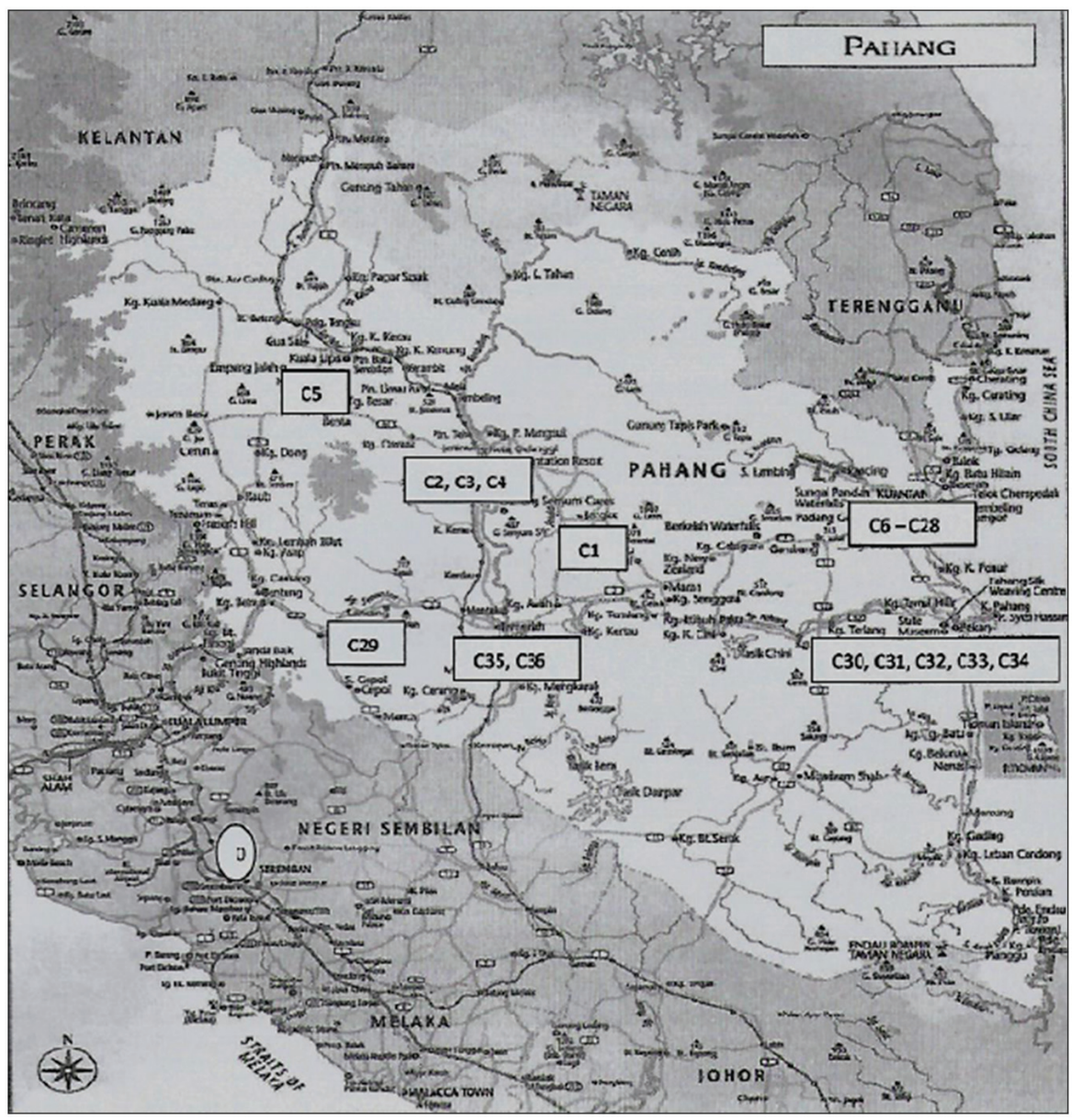

Figure 1 Map of customers location. 
area which lead to the unavailability of the data. Therefore, data cleaning is done by combining all of the customers in different locations to be within the same clustered area. For the present case study, the analyses are divided into two phases. The first phase is having all chickens delivered from the main distribution centre and described as One Depot. In the analysis the best planning route for delivery is chosen while minimizing the total travel distance and at the same time determining the number of lorry use. The second phase is when the transhipment point is identified using $p$-centre and to be the second distribution centre and described as Two Depot. Similarly, the best planning route for delivery is chosen while minimizing the total travel distance and at the same time determining the number of lorry use.

Table 5 shows the vehicle type which is the size of lorry such as small lorry and large lorry, capacity of the lorry and cost per delivery. Each customer is served by one or more facilities with specified transportation links. Moreover, each outsource transportation has a fixed capacity to deliver customers demand. Furthermore, the total chicken out per delivery takes about maximum 1000 of chickens when customers request for the small lorry and maximum 2300 of chickens when customers request for the large lorry, based on customers' demands. In addition, each delivery is charged about RM 500 per delivery for small lorry otherwise each delivery is charged about RM 800 per delivery for large lorry.

\subsubsection{Result for Phase 1 - One Depot}

Tables 6 and 7 show the results when all chickens are delivered from the main distribution centre or one depot only.

\subsubsection{Result for Phase 2 - Two Depots}

The transhipment point $\mathrm{C} 1$ is chosen using $p$-centre and the chickens are delivered from both the main distribution centre $(0)$ and from $\mathrm{C} 1$. The best route is determined using Excel Solver and 15 customers get their delivery directly from the main distributor while the balance two (12) customers get it from the transhipment point $\mathrm{C} 1$. Note that $\mathrm{C} 1$ also gets its supply from the main distributor. Total distance travel by all chickens are summarised in Tables 8 and 9.

Table 5 Vehicle type, capacity of lorry and cost per delivery

\begin{tabular}{lll}
\hline Vehicle Type (Size of Lorry) & Capacity of the Lorry & Fixed Cost Per Delivery \\
\hline Small & 1000 chickens per delivery & RM 500 \\
Large & 2300 chickens per delivery & RM 800 \\
\hline
\end{tabular}


Table 6 Average traveled distance using small lorry

\begin{tabular}{llcc}
\hline Number of Lorry & Routes & No. of Chickens & Distance Traveled \\
\hline First & Depot-C13 & 1000 & 326700 \\
Second & Depot-C13 & 1000 & 326700 \\
Third & Depot-C6-C7-C10-C11-C12- & 740 & 241758 \\
& C14-C17-C18-C19-C21-C23 & & \\
Forth & Depot-C13-C30-C32-C1 & 850 & 326647 \\
Fifth & Depot-C29-C36 & 130 & 19686 \\
\hline Total & & 3720 & 1241491 \\
\hline Average travel distance per chicken & & 333.73 \\
\hline
\end{tabular}

Table 7 Average traveled distance using large lorry

\begin{tabular}{llcc}
\hline & & No. of Chickens \\
Number of Lorry & Routes & 2300 & 751410 \\
First & Depot-C13 & 1420 & 484049 \\
Second & Depot-C6-C7-C10-C11-C12- & & \\
& C13-C14-C17-C18-C19-C21- & & \\
Total & C23-C30-C32-C1-C29-C36 & 3720 & 1235459 \\
\hline Average travel distance per chicken & & 332.11 \\
\hline
\end{tabular}

Table 8 Delivery from transhipment point C1

\begin{tabular}{llcc}
\hline No. of Lorry & Routes & No. of Chickens & Total Distance \\
\hline First & Depot-C1-C13 & 2640 & 121440 \\
Second & Depot-C1-C6-C7-C10-C11-C12-C13- & 950 & 165550 \\
& C14-C17-C18-C19-C21-C23-C30-C32 & & \\
\hline Total & & 3590 & 286990 \\
\hline Average travel distance by each chicken & & 79.94 \\
\hline
\end{tabular}

Table 9 Delivery from main depot

\begin{tabular}{llcc}
\hline Number of Lorry & Routes & No. of Chickens & Total Distance \\
\hline First & Depot-C36-C29 & 130 & 4316 \\
Total & & 130 & 4316 \\
\hline Average travel distance by each chicken & & 33.2 \\
\hline
\end{tabular}

In Section 3.3.1, the results show that the size of lorry does not contribute to lower distance traveled by each unit of the chicken. However, comparing the results in Sections 3.3.1 and 3.3.2, we can see that by having the transhipment point the average traveled distance can be reduced tremendously from 333.73 (using small lorry) and 332.11 (using large lorry) to only 79.94 from the transhipment point and only 33.2 from the main depot. 


\section{Conclusion}

In this paper, we have proposed a new way of determining the transshipment point among the customers for location routing inventory problem. The selection of routes in this analysis are randomly picked and tested in order to achieve the maximum distance that has the minimum total system cost. The total system cost has considered the new technique of choosing the transshipment point using $p$-center. This technique has excluded some costs and only has the total distance travelled in the formulation and applied into the real life problem and see tremendous improvement. In future research, we will further consider using the heuristic method called genetic algorithm for a better route's selection. Another area of possible research involves LRIP-T together with development of new algorithm is the stochastic demand. For real life problem, fluctuation of customer's demand also needs to be considered.

\section{Acknowledgement}

We would like to acknowledge Ministry of Higher Education Malaysia for funding this research through the Research Management Institute (RMI) of Universiti Teknologi MARA, Malaysia, Grant No: 600-RMI/FRGS $5 / 3(9 / 2013))$ and ICatse for the invitation of this special issue.

\section{References}

[1] Xuefeng, W. (2010). "An integrated multi-depot location-inventoryrouting problem for logistics distribution system planning of a chain enterprise" in Logistics Systems and Intelligent Management, 2010 International Conference on 3, Nanchang China: IEEE, 1427-1431.

[2] Granada, M. G., and Silva, C. W. (2012). "Inventory location routing problem: a column generation approach." in Proceedings of the 2012 International Conference on Industrial Engineering and Operations Management, Istanbul, Turkey, 482-491.

[3] Bertazzi, L., Paletta, G., and Speranza, M. G. (2002). Transportation Science, 36, 119-132.

[4] Kleywegt, A. J., Nori, V. S., and Savelsbergh, M. W. P. (2002). Transportation Science, 36, 94-118.

[5] Zhao, Q. H. (2003). "Study on logistics optimization models", PhD thesis, Beihang University. 
[6] Yang, F. M., and Xiao, H. J. (2007). Systems Engineering, Theory \& Practice, 27, 28-35.

[7] Zhang, B., Ma, Z., and Jiang, S. (2008). "Location routing inventory problem with stochastic demand in logistics distribution systems", In Proceeding of: Wireless Communications, Networking and Mobile Computing, IEEE Xplore, 1-4.

[8] Ahmad, H., Hamzah, P., Md Yasin, Z. A. M., and Shariff, S. S. R. (2014). "Location Routing Inventory Problem with Transshipment (LRIP-T)" in Proceedings of the 2014 International Conference on Industrial Engineering and Operations Management, Bali, Indonesia, 1595-1605.

[9] Shariff, S. S. R., Omar, M., and Moin, N. H. (2016). "Location Routing Inventory Problem with Transshipment Points Using p-Center", in 2016 International Conference on Industrial Engineering, Management Science and Application (ICIMSA), Jeju, South Korea, 1-5.

\section{Biographies}

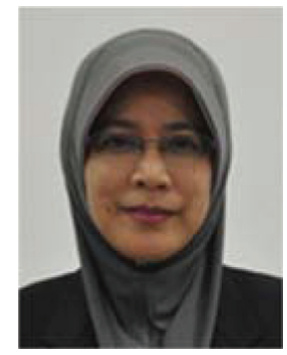

S. S. R. Shariff is currently a fulltime senior lecturer at the Centre for Statistical and Decision Science Studies at the Faculty of Computer and Mathematical Sciences of Universiti Teknologi MARA (UiTM), Shah Alam, Malaysia. Dr. Shariff earned a Bachelor of Science degree in Statistics and Mathematics from Purdue University, West Lafayette, Indiana, USA, a Master in Information Technology from UiTM, Shah Alam and Ph.D. in Operational Research from University of Malaya, Kuala Lumpur. She is the Head of Research Interest Group for Logistics Modelling and has published and reviewed journal and conference papers. Her research interests include facility location modeling, logistics process modeling, warehousing, inventory routing, optimization and performance measurement. She is the Secretary for Management Science/Operations Research Society of Malaysia (2013-2017), 
a member of INFORMS, and a Lifetime Member of Mathematical Society of Malaysia (PERSAMA).

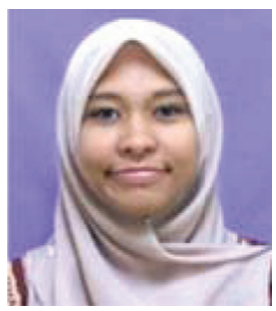

N. S. Kamal is a final year student at UiTM, pursuing a Master degree in Quantitative Sciences. Upon graduation, she works as a planner in a company.

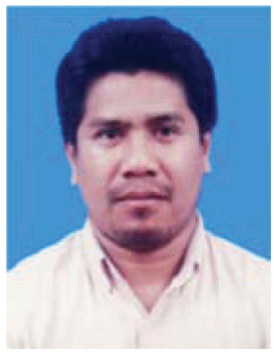

M. Omar is a full Professor at Institute of Mathematical Sciences, University of Malaya, Kuala Lumpur. His research interests include but not limited to Industrial Optimisation and Control (Production Planning, Vendor-Buyer, Optimal Policy.

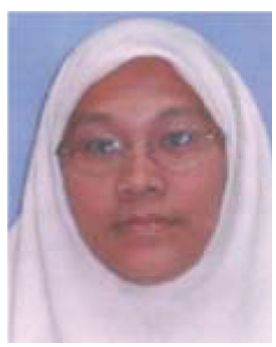

N. H. Moin is an Associate Professor at Institute of Mathematical Sciences University of Malaya, Kuala Lumpur. Her research interests are Vehicle 
72 S. S. R. Shariff et al.

Routing, Inventory Routing, Production Inventory Distribution Routing Problem, Scheduling, Metaheuristics (Genetic Algorithm, Ant Colony, Artificial Bee, Variable Neighborhood Search), Matheuristic (Combination of Linear Programming Technique and Metaheuristic). (Vehicle Routing, Inventory Routing, Production Inventory Distribution Routing Problem, Scheduling, Metaheuristics, Matheuristic) 